could achieve, and that some patients needed further discussion before referral was made.

RICHARD TILLETT

Wonford House Hospital

Wonford, Exeter

EX2 $5 A F$

\section{Mental Health Review Tribunals in practice}

DeAr Sirs

It has been drawn to my attention that the references for my paper (Psychiatric Bulletin, June 1993, 17 , 331-336) contain two errors and an omission.

(a) There is a third edition of Richard Jones' Mental Health Act Manual published in 1991.

(b) The reference to the 'Mental Health Act Manual', DOH, should read 'Mental Health Act 1983, Memorandum on Parts I to VI, VIII and X', Department of Health. London: HMSO.

(c) Mental Health: Tribunal Procedure (1992) L. Gostin \& P. Fennell, Longmans.

GoRDON LANGLEY

Hanningfields

Warnborough Hill

Kenton

Exeter EX6 8LR

DeAR Sirs

Gordon Langley has provided a valuable service to Tribunal members and non-members alike in his paper on 'Mental Health Review Tribunal practice' (Psychiatric Bulletin, June 1993, 17, 331-336). In addition to the references he quotes, new Tribunal members are provided (among other material) with $A$ Guide For Members produced by a small group of us in 1988. In addition, both new and experienced members will find Larry Gostin's and Phil Fennell's Mental Health: Tribunal Procedure (second ed, Longman, 1992) a most useful aid to practice. (See David Tidmarsh's review of it in the June issue of the Journal, p. 860).

Herschel Prins

Loughborough University

Lay Member, MHRT-Trent Region

Loughborough LE11 $3 T U$

\section{Clozapine withdrawal syndrome}

\section{DeAR SIRS}

I was interested to read Palia \& Clarke's description of a possible clozapine withdrawal syndrome (Psychiatric Bulletin, June 1993, 17, 374-375). My own experience of treating 20 patients with this drug confirms that the inevitable rebound that one witnesses on stopping it suddenly is worsened by a confusional state which varies in severity from patient to patient. Because of my awareness of this, the last time I took a patient off the drug (for reasons other than a red alert), I weaned the patient off a dose of $375 \mathrm{mgs}$ daily over three weeks (the latest Clozaril data sheet suggesting gradual reduction over one to two weeks). Despite this, the confusional state that accompanied the rebound psychosis was most marked, and led to the patient having to be nursed in pyjamas for one week. This patient had been taking clozapine for over two years, and I wonder whether the weaning off period should be extended to a month or more if the patient is well established on the drug (say a minimum of 18 weeks, which is the time that blood testing changes from weekly to fortnightly).

I look forward to reading or hearing of others' experience in this area.

Warley Hospital

E. MeLtZer

Warley Hill, Brentwood

Essex CMI4 $5 \mathrm{HQ}$

\section{Hypnosis in psychiatry}

\section{DEAR SiRS}

Dr Mathew on 'Hypnosis in Psychiatry' (Psychiatric Bulletin, April 1993, 17, 202-204) concludes that "Hypnotherapy should be considered as a supportive and supplementary therapy and not as a substitute form of therapy to treat the untreatable." What exactly does he mean? A "substitute" for what? And, how can the "untreatable" be "treated"?

There are numerous examples of hypnosis as a treatment in its own right as distinct from being merely "supportive" or "supplementary", as in severe refractory irritable bowel syndrome (Whorwell et al, $1984,1987)$ and infertility without any organic basis (Mackett, 1985). I recently treated two cases in which AID had been attempted unsuccessfully over a prolonged period. The patients were referred by a consultant in infertility. Both became pregnant within months.

I agree with the author that psychiatric patients should not consult those with no medical qualifications and no formal training in psychiatry. But why pick on the practice of hypnosis in this connection? For similar reasons, I have never been in favour of the direct referral of psychiatric problems to clinical psychologists.

Mathew concludes that hypnosis is valuable in liaison psychiatry where specialists have not discovered any organic abnormality. This may or may not be true, but diagnosis (and therefore therapy) should be based on positive grounds, not merely on 